\title{
DO OWNERSHIP OF MOSQUITO NETS, DWELLING CHARACTERISTICS AND MOTHERS' SOCIO-ECONOMIC STATUS INFLUENCE MALARIA MORBIDITY AMONG CHILDREN UNDER THE AGE OF 5 IN CAMEROON?
}

\author{
ABAYOMI SAMUEL OYEKALE \\ North-West University, Mmabatho, South Africa \\ Department of Agricultural Economics and Extension
}

\begin{abstract}
Objectives: This study analyzed the effect of the number of mosquito nets that are owned by households, dwelling characteristics and maternal demographic characteristics on malaria infections. Material and Methods: The 2011 Demographic and Health Survey (DHS) data for children under 5 years of age were used. The children were subjected to haemoglobin test and rapid diagnostic test (RDT) to ascertain the presence of malaria parasites. Data were analyzed using probit regression method. Results: It was found that $2.43 \%$ and $8.68 \%$ of the children were living in houses that were prone to landslide and flooding, respectively. Also, $19.93 \%, 17.08 \%$ and $16.26 \%$ of the children lived in houses without windows, with broken windows, and with a hole in the roof, respectively. Only $5.59 \%$ and $23.96 \%$ of the children lived in houses with window and door nets, respectively. Mosquito nets were owned by $64.03 \%$ of the households, where Adamawa Region had the lowest coverage (52.23\%). Reasons for not owning mosquito nets by all the households included: lack of financial means $(25.17 \%)$, using something else $(1.80 \%)$ and not having many mosquitoes in the vicinity $(5.53 \%)$. In the probit regression, variables that significantly reduced malaria infections among the children $(\mathrm{p}<0.05)$ included: the number of mosquito nets, urban residence, improved toilet, ownership of a radio, residence in flood-prone area, mother's secondary education, mother's tertiary education and residence in areas with not many mosquitoes, while infections increased along with the household size, residence in areas prone to landslide, severe anaemia, moderate anaemia, mild anaemia and age of the children. Conclusions: Ownership of mosquito nets and dwelling characteristics are critical factors influencing infections with malaria. There is a need to ensure compliance with its use since there are disparities between access and actual usage. Also, addressing malaria problem in Cameroon should consider regional disparity in malaria incidence rates and more engagement of the media, among others, for appropriate sensitization.
\end{abstract}

Key words:

Malaria, Mosquito nets, Under-5 children, Cameroon

\section{INTRODUCTION}

Malaria is caused by infection from protozoan of the genius Plasmodium, which is transmitted through mosquito bites. The disease constitutes a serious health hazard in many tropical countries due to favorability of the climate for mosquito breeding [1,2]. Some statistics have shown that 300-500 million cases of malaria are reported annually, with more than 1 million deaths [3]. More than $90 \%$

Received: May 26, 2014. Accepted: September 28, 2014.

Corresponding author: A.S. Oyekale, North-West University, Department of Agricultural Economics and Extension, Mafikeng Campus, Mmabatho 2735, South Africa (e-mail: asoyekale@gmail.com). 
of malaria cases and $75 \%$ of associated deaths occur in Sub-Saharan Africa (SSA) [3,4]. Some estimates indicate that 207 million cases of malaria and 627000 deaths were reported in 2012 [5]. These statistics represent only a slight reduction from 219 million malaria episodes and 660000 deaths estimated for 2010 [6]. Also, 14 countries accounted for $80 \%$ of malaria deaths and about $80 \%$ of the estimated cases occurred in 17 countries. In Africa, malaria was ranked by the World Bank and World Health Organization (WHO) as the leading cause of lost disability adjusted life years (DALYs) with the total estimated annual loss of 35 million future life years [7].

In Cameroon, malaria is responsible for $30-35 \%$ of total annual death cases. It also accounts for $35 \%$ of childhood mortality and $40-45 \%$ of the reported cases of morbidity [8]. It has been estimated that about $41 \%$ of total Cameroon's population records at least one malaria episode annually, although pregnant women and children under the age of 5 are usually more vulnerable [8]. This implies that about 8.2 million people suffer from malaria attacks each year [9]. Another estimate indicates that malaria is the principal cause of morbidity in Cameroon, accounting for about $35-40 \%$ of deaths of hospitalized patients, $50 \%$ of illness and morbidity in the children under 5 years of age, about $40 \%$ of the under- 5 children mortality and $40-45 \%$ of medical consultations [10].

Access to insecticide-treated net (ITN) is one of the major ways of preventing transmission of malaria parasites through mosquito bites within a population setting. At a household level, various cultural, ethnic, behavioral and demographic factors influence acceptability of ITNs for use [11-17]. Some studies have demonstrated effectiveness of ITNs in combating malaria-related morbidity and mortality [18-21]. Others have found the efficacy of ITNs in reducing malaria-related morbidity though with a varying degree of effectiveness [11,22-24]. Non-continuity in the use of ITN is also an important issue [25]. It has been noted that the size of a household and the size of a house are critical issues of concern [12,13]. These can be explained by the fact that households with small rooms often complain of high room temperature at night which prevents sleeping under mosquito nets. Also, in a large family, there is very low likelihood that everybody will sleep under a mosquito net.

Characteristics of the place of dwelling can influence breeding of mosquitoes and exposure of household members to their bites. For instance, poorly maintained drainage, bushy environment, stagnant water and dirty environment are breeding grounds for mosquitoes [7]. Also, malaria can disproportionately affect rural and urban children for several reasons. Specifically speaking, unplanned urbanization which results in poor housing, inadequate sanitation and poorly managed drainage systems is a major facilitator of malaria due to rapid multiplication of mosquito population [26].

Higher but insignificant interaction between the prevalence of malaria parasites among some school children and residential characteristics have been reported for Southwest Cameroon [27]. Another study in Douala and Yaoundé cities of Cameroon [9] has found that methods adopted for preventing malaria included: ensuring environmental sanitation (76.1\%), sleeping under bed nets $(69 \%)$, using insecticide spray/coils (12.3\%) and adequate netting of doors or windows $(1.9 \%)$. These findings are highly different from what has been found in a study in India [28] where $94 \%$ of the respondents used at least one pesticide to control mosquitoes.

Moreover, Kimbi [27] has reported that effectiveness of ITN could have been compromised by difficulty in finding chemicals needed for retreatment (47\%), outdated available bed nets and financial difficulties in purchasing other $(24.5 \%)$ as well as restless sensation due to excessive heat when sleeping under a bed net $(5 \%)$. Some of these reasons were raised in another study [27], where it has been found that children that were sleeping under ITNs had higher prevalence of malaria parasites in Southwest 
Cameroon. The findings raised the question of whether ownership of mosquito nets implies usage and the fact that even if used, household members can be exposed to mosquito bites elsewhere.

Another study in Cameroon [29] has found that malaria burden was disproportionately borne by women of very low socio-economic status including the unemployed, those that are unable to afford modern housing facilities, and those living in the neighborhood with high concentration of the poor. This implies that children and individuals with malaria infection would most likely be anaemic. In Cameroon, similar result have been reported [27,29]. Furthermore, rural children more frequently than those from urban areas may not have access to adequate nutrition due to prevailing poverty. However, malaria infections can have more serious consequences among children with clinical and sub-clinical malnutrition [7]. This results from the low disease resistance of malnourished children. Research has shown that in many cases, iron deficiency among children is positively correlated with malaria infections, while malaria parasite density and plasma iron concentrations are negatively correlated [30,31]. Some studies have, therefore, emphasized adequate nutrition as panacea for the disease infection among children [32].

Similarly, there may be a significant interaction between a mother's education and family wealth. These variables interact with malaria infection in different ways because an educated mother may be able to secure a better job, have better income and live in cleaner environment with basic social amenities. Exposure to malaria parasites of children that live in such area may be less than that of children whose mothers are illiterate and who live in a poorly developed area [33].

The age of the child is another factor that can influence malaria infection. As children grow older, their immune system builds up for adequate resistance against various diseases. However, vulnerability to malaria may generally increase as the child grows older due to the tendency of not sleeping under mosquito nets. In a study that was conducted among school children in Southwest Cameroon, the highest prevalence of malaria has been found among children in the youngest age group ( $<6$ years) [27]. Using the most recent Demographic and Health Survey (DHS) data, this study determined the effect of ITN usage, features of the households' dwelling and maternal socio-economic characteristics on the infection with malaria parasites among children under the age of 5 in Cameroon.

\section{MATERIAL AND METHODS}

\section{Study area}

Cameroon has a land area of $475400 \mathrm{~km}^{2}$, and it is administratively divided into 10 provinces: Adamawa (Adamoua), Centre/Yaounde, East (Est), Far North (Extreme Nord), Littoral/Douala, North (Nord), North West (Nord Quest), West (Quest), South (Sud), and South West (Sud Quest). There are 4 distinct vegetation and topographical landforms in the country: the southern region's low coastal plain with equatorial rainforests and swamp lands; savannah plateau in the centre, which is also referred to as the Adamaoua Plateau; the mountainous west, and southwestern region with forest cover extending to Mount Cameroon or Mount Fako, as well as a sub-arid savannah in the north. The country has a tropical climate, varying from the humid equatorial region in the south to the dry Sahel savanna in the north. Households in the Sahel savannah have a wet season (April and September) with an average annual rainfall of 1000-1750 mm, while the southern equatorial region has 2 wet and 2 dry seasons with each having peaks of wet and dry and average annual precipitation of $4030 \mathrm{~mm}$. The coastal regions have an average annual rainfall of about $4060 \mathrm{~mm}[33,34]$.

\section{Data and sampling methods}

The 2011 standard DHS data for Cameroon covered nationally representative households after questionnaires were satisfactorily pre-tested. The detailed procedures 
for training enumerators and data collection had been provided [35]. The samples were collected using 2-stage stratified sampling and households were selected proportionally to the size with an adequate coverage of 10 administrative regions and the 2 major cities of Yaounde and Douala. It is, therefore, important to note that the results for the Centre and Littoral Regions excluded the samples from Yaounde and Douala. The 1st stage of the sampling involved selection of primary Enumeration Areas (EAs) based on the list for the 3rd General Census of Population and Housing Census (PHC) in 2005.

In total, 580 EAs were selected comprising 289 from the rural areas and 291 from the urban ones. Definition of rural area was based on having population density of less than 20 000. Most of these places normally lack basic social services like electricity, good road networks and portable water. Households in each of the EAs formed the sampling unit for the 2nd stage, whereby systematic sampling with equal selection probability was used. Out of the selected EAs, 578 were sampled. However, out of the target population of 15050 households, 14354 were identified and 14214 were successfully interviewed. Similarly, within the selected 14214 households 15852 eligible women (aged 15-49 years) were found, of who 15426 were successfully interviewed.

All the women and children were subjected to haemoglobin test in order to determine the prevalence of anaemia. Also, all the children 6-59 months old (6623 in number) were eligible and subjected to malaria test. The protocols for conducting these tests were approved by the National Informed Consent Form Ethics of Cameroon and the Ethics Committee (Institutional Review Board) Committee International. Enumerators were adequately trained to perform haemoglobin and malaria tests after obtaining consent from the parents. The HemoCue system was used to perform haemoglobin test, while malaria rapid diagnostic test (RDT) was used to ascertain the presence of malaria parasites in the blood samples collected by thumb pricking.

\section{Model specification}

Econometric modelling of being tested positive to malaria parasites can be addressed with probit model since the responses can be categorized into 2 groups (positive or negative). Dealing with such a model requires the use of maximum likelihood estimates (MLE) in the estimation of the parameters, because ordinary least square (OLS) would produce biased and inefficient parameters. In this instance, it had been submitted that probit modelling is based on latent model expressed as [36]:

$$
\mathrm{P}\left(\mathrm{y}_{\mathrm{i}}=1 \mid \mathrm{x}\right)=\left(\mathrm{y}_{\mathrm{i}}^{*}>0 \mid \mathrm{x}\right)
$$

where:

$\mathrm{x}$ - explanatory variables,

$y_{i}$ - infection with malaria (yes $=1,0$ otherwise),

$y_{i}^{*}$ - estimated latent form of $y_{i}$,

$$
=\mathrm{P}\left(\mathrm{x}_{\mathrm{i}}^{\prime}+\varepsilon_{\mathrm{i}}>0 \mid \mathrm{x}\right)
$$

where:

$\mathrm{x}_{\mathrm{i}}^{\prime}$ - latent independent variable,

$\varepsilon_{\mathrm{i}}$ - error term,

$$
=\mathrm{P}\left(\varepsilon_{\mathrm{i}}>\mathrm{x}_{\mathrm{i}}^{\prime} \beta \mid \mathrm{x}\right)
$$

where:

$\beta$ - estimated parameters,

$$
=1-\mathrm{F}\left(\mathrm{x}_{\mathrm{i}}^{\prime} \beta\right)
$$

The error terms are normally distributed and independent, therefore:

$$
\mathrm{P}\left(\mathrm{y}_{\mathrm{i}}=1 \mid \mathrm{x}\right)=1-\phi\left(-\frac{\mathrm{x}_{\mathrm{i}}^{\prime} \beta}{\sigma}\right), \sigma \equiv 1
$$

where:

$\phi-$ probability distribution function,

because of symmetry assumption:

$$
=1-\phi\left(-\frac{x_{\mathrm{i}}^{\prime} \beta}{\rho}\right)=\phi\left(\mathrm{x}_{\mathrm{i}}^{\prime} \beta\right)
$$


The marginal effect measures the effect of a unit change in an independent variable on the probability $\mathrm{P}(\mathrm{Y}=1 \mid \mathrm{X}$ $=\mathrm{x})$ given that all the other variables are held constant. This is computed as:

$$
\frac{\delta \mathrm{P}\left(\mathrm{y}_{\mathrm{i}}=1 \mid \mathrm{x}_{\mathrm{i}}\right)}{\delta \mathrm{x}_{\mathrm{i}}}=\frac{\delta \mathrm{E}\left(\mathrm{y}_{\mathrm{i}} \mid \mathrm{x}_{\mathrm{i}}\right)}{\delta \mathrm{x}_{\mathrm{i}}}=\varphi\left(\mathrm{x}_{\mathrm{i}}^{\prime} \beta\right) \beta
$$

where:

$\delta$ - partial differentiation,

$\varphi$ - functional specification.

In the estimation of the model, the independent variables that were included are as follows: the number of mosquito nets, household size, Adamawa Region (yes $=1,0$ otherwise), Centre Region (yes $=1,0$ otherwise), Douala City (yes $=1,0$ otherwise), East Region (yes $=1,0$ otherwise), Far North Region (yes $=1,0$ otherwise), Littoral Region (yes $=1,0$ otherwise), North Region (yes $=1,0$ otherwise), North West Region (yes $=1,0$ otherwise), West Region (yes $=1,0$ otherwise), South Region (yes $=1,0$ otherwise), South West Region (yes $=1,0$ otherwise), urban residence (yes $=1,0$ otherwise), improved water (yes $=1,0$ otherwise), improved toilet (yes $=1,0$ otherwise), electricity (yes $=1,0$ otherwise), radio (yes $=1,0$ otherwise) and television (yes $=1,0$ otherwise).

Other included variables were: gender of a household head (male $=1,0$ otherwise), age of the head, shared toilet (yes $=1,0$ otherwise), dwelling in a land slide area (yes $=1,0$ otherwise), dwelling in a flood area (yes $=1,0$ otherwise), dwelling in a riverside (yes $=1,0$ otherwise), dwelling in a steep hill (yes $=1,0$ otherwise), dwelling near a refuse depot (yes $=1,0$ otherwise), dwelling near industrial pollution (yes $=1,0$ otherwise), no window (yes $=1,0$ otherwise), broken window (yes $=1,0$ otherwise), hole in the roof (yes $=1,0$ otherwise), incomplete roof (yes $=1,0$ otherwise), window nets (yes $=1,0$ otherwise), door nets (yes $=1,0$ otherwise), no net due to the lack of means (yes $=1,0$ otherwise), mosquito net is not necessary (yes $=1,0$ otherwise), using something else (yes $=1,0$ otherwise), not many mosquitoes (yes $=1,0$ otherwise), child sex (male $=1,0$ otherwise), mother alive, father alive (yes $=1,0$ otherwise), mother with primary education (yes $=1,0$ otherwise), mother with secondary education (yes $=1,0$ otherwise), mother with tertiary education (yes $=1,0$ otherwise), age in months, severe anaemia (yes $=1,0$ otherwise), moderate anaemia (yes $=1,0$ otherwise) and mild anaemia (yes $=1,0$ otherwise).

\section{RESULTS}

\section{Demographic characteristics}

of children and their parents

The results of descriptive statistics of some socio-economic variables of the children and their parents are presented in Table 1. It reveals that an average household size for the whole sample was 8.14 persons. Also, the computed mean household size for the rural areas (8.43) was significantly higher than that for the urban areas (7.72) $(\mathrm{F}=42.45$, $\mathrm{p}<0.01)$. The average age of the household heads in the combined data set was 44.78 years, and there was a significant difference in average ages of household heads across the regions $(F=21.41, p<0.01)$. Across the country's economic sector, household heads in the rural areas had significantly higher average age (45.77 years) than those in the urban ones (43.36 years) $(\mathrm{F}=47.65, \mathrm{p}<0.01)$.

The average age of all the children was 2.29 years and there was a significant difference in the ages of children across the regions $(\mathrm{F}=2.954, \mathrm{p}<0.01)$. The children from the rural areas were also slightly older with an average age of 2.32 years than their urban counterparts with an average age of 2.24 years. However, these average ages showed no significant difference $(\mathrm{F}=2.24, \mathrm{p}>0.10)$. Table 1 further shows the percentage distribution of demographic characteristics of the children's households' heads and their mothers. In the rural and urban 
Table 1. Descriptive statistics of the parents' and children's demographic characteristics

\begin{tabular}{lccc}
\hline \multirow{2}{*}{ Socio-economic characteristics } & \multicolumn{3}{c}{ Respondents } \\
\cline { 2 - 4 } & $\begin{array}{c}\text { rural } \\
(\mathrm{N}=3907)\end{array}$ & $\begin{array}{c}\text { urban } \\
(\mathrm{N}=2716)\end{array}$ & $\begin{array}{c}\text { total } \\
(\mathrm{N}=6623)\end{array}$ \\
\hline Household size (M) [persons] & 8.43 & 7.72 & 8.14 \\
Age (M) [years] & & & 44.78 \\
$\quad$ household head & 45.77 & 43.36 & 2.29 \\
child & 2.32 & 2.24 & 81.46 \\
Male [\%] & & & 49.01 \\
head & 83.18 & 78.98 & \\
child & 49.01 & 49.01 & 98.90 \\
Alive parent [\%] & & & 97.03 \\
mother & 98.87 & 98.93 & \\
father & 96.72 & 97.46 & 45.27 \\
Mother's education [\%] & & & 31.30 \\
none & 52.29 & 35.16 & 21.35 \\
primary & 34.76 & 26.33 & 2.08 \\
secondary & 12.41 & 34.20 & \\
tertiary & 0.54 & 4.31 & \\
\hline
\end{tabular}

$\mathrm{M}-$ mean.

areas, $83.18 \%$ and $78.98 \%$ of the household heads respectively, were male. The table also reveals that in the rural and urban areas, male children accounted for $49.01 \%$ of all the children. Also, majority of mothers and fathers of the children were alive although the percentages of fathers alive were lower than mothers alive across the rural/urban areas.

\section{Dwelling characteristics, access to mosquito nets and the incidence of malaria}

Table 2 shows physical characteristics of the houses where the children were living and access of their parents to basic housing facilities. It reveals that in the rural and urban areas, $2.43 \%$ of the children were each living in areas prone to landslides. Children from the rural areas that resided in a riverside constituted $7.32 \%$ compared to $6.41 \%$ for the urban children. A higher proportion of children from the rural areas (8.98\%) lived on steep hills in comparison with $7.62 \%$ for the urban children. In the rural areas, $0.87 \%$ of the children lived in areas with industrial pollution, while this proportion for the urban area was $1.29 \%$.

The extent of deprivation in some critical housing attributes was reported by some households. The implications of such deprivation for malaria prevention can be judged from inability to prevent entrance of mosquitoes into the house. Specifically speaking, some children resided in houses with no windows. A higher proportion of the rural children $(27.39 \%)$ lived in houses without windows when compared to the urban children $(9.2 \%)$. Also, some of the windows in dwellings where the children resided were reported to have been broken in the rural and urban areas with $16.53 \%$ and $17.86 \%$, respectively. A higher proportion of children from the rural areas $(18.45 \%)$ reported 
Table 2. Features of the children's dwellings and ownership of mosquito nets

\begin{tabular}{|c|c|c|c|}
\hline \multirow[t]{2}{*}{ Variable } & \multicolumn{3}{|c|}{$\begin{array}{c}\text { Respondents } \\
{[\%]}\end{array}$} \\
\hline & rural & urban & total \\
\hline \multicolumn{4}{|l|}{ Dwelling characteristic } \\
\hline land slide areas & 2.43 & 2.43 & 2.43 \\
\hline flood areas & 7.29 & 10.68 & 8.68 \\
\hline riversides & 7.32 & 6.41 & 6.95 \\
\hline steep hills & 8.98 & 7.62 & 8.43 \\
\hline near refuse depots & 0.67 & 2.72 & 1.51 \\
\hline industrial pollution & 0.87 & 1.29 & 1.04 \\
\hline no window & 27.39 & 9.20 & 19.93 \\
\hline window broken & 16.53 & 17.86 & 17.08 \\
\hline hole in the roof & 18.45 & 13.11 & 16.26 \\
\hline incomplete roof & 3.89 & 2.03 & 3.13 \\
\hline window nets & 3.10 & 9.17 & 5.59 \\
\hline door nets & 17.15 & 33.76 & 23.96 \\
\hline improved water & 48.58 & 88.59 & 64.99 \\
\hline improved toilet & 1.25 & 15.98 & 7.29 \\
\hline electricity & 20.14 & 85.27 & 46.85 \\
\hline \multicolumn{4}{|l|}{ Mosquito net ownership } \\
\hline has mosquito nets & 63.40 & 64.95 & 64.03 \\
\hline all children slept under mosquito nets & 19.04 & 29.05 & 23.15 \\
\hline positive malaria test & 40.54 & 23.12 & 33.40 \\
\hline severe anaemia & 2.18 & 0.99 & 1.69 \\
\hline moderate anaemia & 28.67 & 23.49 & 26.54 \\
\hline mild anaemia & 21.81 & 23.16 & 22.36 \\
\hline no net due to the lack of means & 28.38 & 20.54 & 25.17 \\
\hline no net because it is not necessary & 0.95 & 2.87 & 1.74 \\
\hline the use of something else & 1.10 & 2.80 & 1.80 \\
\hline not many mosquitoes & 4.27 & 7.33 & 5.53 \\
\hline
\end{tabular}

holes in the roofs and this can be compared with $13.11 \%$ in the case of the urban children.

Also, some houses where the children lived had incomplete roofs. Specifically, the rural areas had higher percentage of the houses having incomplete roofs with $3.89 \%$ as against $2.03 \%$ for the urban areas. Presence of improved water was reported by $64.99 \%$ of the total of respondents.
In the rural areas, $48.58 \%$ had access to improved water sources, as against $88.58 \%$ in the urban areas. Access to improved sanitation signifies reduction in the rate of exposure to disease causing pathogens and avoidance of providing veritable breeding grounds for mosquitoes. Access to improved toilet was reported by $7.29 \%$ of the total of respondents, while $1.25 \%$ and $15.98 \%$ were 
in the rural and urban areas, respectively. Similar results were found with respect to the access to electricity with $85.27 \%$ reported cases of access in the urban areas and only $20.14 \%$ in the rural areas.

Table 2 shows access to mosquito nets in relation to the incidence of malaria and severity of anaemia among the children. The percentages of rural children whose households had mosquito nets were 63.4 and 64.95 in the rural and urban areas, respectively. However, the proportion of the urban households that indicated that all the children slept under mosquito nets was $29.05 \%$, while for the rural households it was $19.04 \%$. Also, in the course of the survey, all the children were subjected to malaria test. The result showed that $40.54 \%$ of the children from rural areas were tested positive to malaria in comparison with $23.12 \%$ in the urban areas. All the children were also subjected to heamoglobin test. Higher proportions of the rural children were severely anemic and moderately anemic with $2.18 \%$ and $28.67 \%$, respectively as against $0.99 \%$ and $23.49 \%$ for the urban children.

Table 2 further shows the reasons that were given by the children's parents for not owning mosquito nets across the regions and sectors in Cameroon. In the rural and urban areas, $28.38 \%$ and $20.54 \%$ of the children's households could not afford to buy mosquito nets due to the lack of the necessary financial means. Also, in the rural and urban areas, $0.95 \%$ and $2.87 \%$ of the households respectively hinted that mosquito nets were not necessary. Compared with the urban areas, a lower percentage of children's households from the rural areas $(1.1 \%)$ submitted that they were using other alternatives to address malaria.

\section{Correlates of malaria infection}

Table 3 presents the results of probit regression which was based on the factors influencing child's infections with malaria. The results show that the model fitted the data very well as shown by statistical significance of the Pearson's Chi ${ }^{2}$ (6935.21, $\left.\mathrm{p}<0.01\right)$. The marginal coefficient of the number of mosquito nets parameter is statistically significant $(p<0.01)$ and shows that if the number of mosquito nets increased by 1 , probability of being infected with malaria was reduced by 0.0319 . The parameters of household gender and age did not show statistical significance $(\mathrm{p}>0.10)$. Household size marginal parameter is statistically significant $(p<0.01)$ and it implies that if a household size increased by 1 person, probability of child being infected with malaria increased by 0.0064 . Across the regions, households from Adamawa Region had a marginal parameter that is statistically significant $(\mathrm{p}<0.01)$. This implies that compared with the children from Yaoundé, which is the base group, residence in Adamawa Region increased the probability of being infected with malaria by 0.1955 . Similar results were obtained in the parameters of East Region (0.1572), South Region (0.1625) and South West Region (0.1283), which are all statistically significant $(\mathrm{p}<0.01)$. All the parameters estimated for the regions in the north (Far North, North and North West) are with a negative sign, although only those of Far North and North West Regions showed statistical significance at $\mathrm{p}<0.05$ and $\mathrm{p}<0.01$, respectively.

Residence in an urban center parameter is with a negative sign and statistically significant $(\mathrm{p}<0.01)$. It implies that the probability of being infected with malaria was reduced by 0.0851 among the children that were residents of urban areas when compared with those that were residents of the rural areas. The variables that captured housing facilities with marginal parameters showing statistical significance are: access to improved water $(\mathrm{p}<0.10)$ and access to an improved toilet $(\mathrm{p}<0.01)$. The results show that compared with those without access, the children with access to improved water had their probability of being infected with malaria reduced by 0.0277 . Also, compared to those without access, the children from households with access to an improved toilet had their probability of having malaria infection decreased by 0.1208 . The relationship 
Table 3. Probit regression results of factors influencing a child's infection with malaria

\begin{tabular}{|c|c|c|c|c|}
\hline \multirow{2}{*}{ Malaria positive result } & \multicolumn{2}{|c|}{ Standard probit } & \multicolumn{2}{|c|}{ Marginal effect } \\
\hline & coefficients & z statistics & coefficients & Z statistics \\
\hline Number of mosquito nets & $-0.0915^{* * *}$ & -4.76 & $-0.03198^{* * *}$ & -4.76 \\
\hline Household size & $0.0183^{* * *}$ & 3.88 & $0.0064^{* * *}$ & 3.88 \\
\hline \multicolumn{5}{|l|}{ Region } \\
\hline Adamawa & $0.5189 * * *$ & 4.78 & $0.1955^{* * *}$ & 4.59 \\
\hline Centre & $0.7520^{* * *}$ & 6.93 & $0.2873^{* * *}$ & 6.82 \\
\hline Douala City & -0.0570 & -0.49 & -0.0196 & -0.50 \\
\hline East & $0.4197^{* * *}$ & 3.73 & $0.1572 * * *$ & 3.57 \\
\hline Far North & $-0.2289 * *$ & -2.07 & $-0.0762 * *$ & -2.18 \\
\hline Littoral & 0.1565 & 1.35 & 0.0564 & 1.31 \\
\hline North Region & -0.0932 & -0.84 & -0.0319 & -0.86 \\
\hline North West & $-0.4845^{* * *}$ & -4.26 & $-0.1493^{* * *}$ & -4.98 \\
\hline West & -0.1439 & -1.30 & -0.0486 & -1.35 \\
\hline South & $0.4328^{* * *}$ & 3.82 & $0.1625^{* * *}$ & 3.65 \\
\hline South West & $0.3454^{* * *}$ & 3.04 & $0.1283^{* * *}$ & 2.90 \\
\hline Urban residence & $-0.2472^{* * *}$ & -4.94 & $-0.08518^{* *}$ & -5.02 \\
\hline Improved water & $-0.0788^{*}$ & -1.95 & $-0.0277^{*}$ & -1.94 \\
\hline Improved toilet & $-0.3832 * * *$ & -4.14 & $-0.1208^{* * *}$ & -4.70 \\
\hline Has electricity & -0.0870 & -1.53 & -0.0303 & -1.53 \\
\hline Has radio & $-0.1435^{* * *}$ & -3.83 & $-0.0503^{* * *}$ & -3.81 \\
\hline Has television & -0.0742 & -1.40 & -0.0258 & -1.40 \\
\hline \multicolumn{5}{|l|}{ Household head } \\
\hline gender & -0.0526 & -1.09 & -0.0185 & -1.08 \\
\hline age & -0.0007 & -0.49 & -0.0002 & -0.49 \\
\hline Shared toilet & 0.0160 & 0.35 & 0.0056 & 0.35 \\
\hline \multicolumn{5}{|l|}{ Area } \\
\hline land slide & $0.2806^{* *}$ & 2.53 & $0.1037^{* *}$ & 2.42 \\
\hline flood area & $-0.2734^{* * *}$ & -3.86 & $-0.0892^{* * *}$ & -4.17 \\
\hline riverside & 0.0506 & 0.74 & 0.0179 & 0.73 \\
\hline steep hill & $-0.2472^{* * *}$ & -3.60 & $-0.0813^{* * *}$ & -3.86 \\
\hline Refuse depot & $-0.3128^{* *}$ & -1.96 & $-0.0995^{* *}$ & -2.19 \\
\hline Industrial pollution & 0.1290 & 0.70 & 0.0464 & 0.68 \\
\hline No window & $0.1331^{* * *}$ & 2.70 & $0.0473^{* * *}$ & 2.65 \\
\hline Window broken & $0.0963^{*}$ & 1.95 & $0.0341^{*}$ & 1.92 \\
\hline Hole in the roof & -0.0553 & -1.12 & -0.0191 & -1.13 \\
\hline Incomplete roof & 0.1268 & 1.25 & 0.0455 & 1.22 \\
\hline
\end{tabular}


Table 3. Probit regression results of factors influencing a child's infection with malaria - cont.

\begin{tabular}{|c|c|c|c|c|}
\hline \multirow{2}{*}{ Malaria positive result } & \multicolumn{2}{|c|}{ Standard probit } & \multicolumn{2}{|c|}{ Marginal effect } \\
\hline & coefficients & z statistics & coefficients & z statistics \\
\hline \multicolumn{5}{|l|}{ Nets } \\
\hline window & 0.1280 & 1.53 & 0.0459 & 1.49 \\
\hline door & $0.1544^{* * *}$ & 3.32 & $0.0549^{* * *}$ & 3.26 \\
\hline none due to the lack of means & -0.0389 & -0.76 & -0.0135 & -0.76 \\
\hline none due to the fact it is not necessary & 0.1068 & 0.74 & 0.0382 & 0.72 \\
\hline Using something else & -0.1196 & -0.88 & -0.0404 & -0.92 \\
\hline Not many mosquitoes & $-0.3645^{* * *}$ & -4.17 & $-0.1151^{* * *}$ & -4.72 \\
\hline Child sex & -0.0038 & -0.11 & -0.0013 & -0.11 \\
\hline \multicolumn{5}{|l|}{ Alive parent } \\
\hline mother & -0.1277 & -0.77 & -0.0459 & -0.75 \\
\hline father & -0.0434 & -0.43 & -0.0153 & -0.43 \\
\hline \multicolumn{5}{|l|}{ Mother's education } \\
\hline primary & -0.0327 & -0.73 & -0.0114 & -0.73 \\
\hline secondary & $-0.1458 * * *$ & -2.59 & $-0.0497^{* * *}$ & -2.66 \\
\hline tertiary & $-0.3098^{*}$ & -1.89 & $-0.0988^{* *}$ & -2.10 \\
\hline Age [in months] & $0.0158^{* * *}$ & 14.21 & $0.0055^{* * *}$ & 14.27 \\
\hline \multicolumn{5}{|l|}{ Anemia } \\
\hline severe & $1.3197^{* * *}$ & 9.88 & $0.4876^{* * *}$ & 12.35 \\
\hline moderate & $0.8250 * * *$ & 17.61 & $0.3046^{* * *}$ & 17.54 \\
\hline mild & $0.3333^{* * *}$ & 6.88 & $0.1210^{* * *}$ & 6.69 \\
\hline Constant & $-0.9471 * * *$ & -4.15 & - & - \\
\hline Observations [n] & \multicolumn{4}{|c|}{6623} \\
\hline Likelihood Ratio Chi (48) & \multicolumn{4}{|c|}{$1420.28^{* * *}$} \\
\hline Pseudo-R ${ }^{2}$ & \multicolumn{4}{|c|}{0.1683} \\
\hline Log likelihood & \multicolumn{4}{|c|}{-3508.4904} \\
\hline Pearson's Chi² (6 525) & \multicolumn{4}{|c|}{$6935.21^{* * *}$} \\
\hline
\end{tabular}

$\mathrm{Chi}^{2}$ - Chi-square test; $\mathrm{R}^{2}$ - pseudo coefficient of determination in probit analysis.

Significant: *** at $1 \%$; ** at $5 \%$; $*$ at $10 \%$.

between access to improved water and malaria can be very complex. Access to a radio parameter is statistically significant $(\mathrm{p}<0.01)$. This implies that compared with the lack of a radio, the radio presence reduced the probability of having malaria infection by 0.0505 .

Some variables were included to capture physical location of the children's dwellings. The results show that the parameter of resident in areas with landslides susceptibility is statistically significant $(\mathrm{p}<0.05)$. This implies that compared to other children, those living in land slide prone areas have their probability of having malaria infection higher by 0.1037 . The parameter that was estimated for residents in flood prone areas is statistically significant $(\mathrm{p}<0.01)$. It also implies that the children that were 
residents in flood prone areas had their probability of having malaria reduced by 0.0892 .

Also, a steep hill variable has a parameter that is statistically significant $(\mathrm{p}<0.01)$. This shows that holding all other factors constant, the probability of having malaria by the children living in houses located on steep hills is reduced by 0.0813 . However, also the parameter of living near a refuse depot variable is statistically significant $(p<0.05)$. It shows that children living near a refuse depot had the probability of contacting malaria reduced by 0.0995 . This may reflect adequate maintenance of such a domestic waste depot.

The parameter of no window variable is also statistically significant $(\mathrm{p}<0.01)$. It implies that holding all other variables constant, the children living in the houses without windows had their probability of contacting malaria increased by 0.0473 . The parameter of having a door net variable is statistically significant too $(p<0.01)$. It implies that if other variables are held constant, children living in the houses with door nets had their probability of being malaria positive increased by 0.0549 .

Out of all the variables that were included to capture reasons for not having mosquito nets, the parameter of not many mosquitoes in the neighborhood is a statistically significant one $(p<0.01)$. This shows that if other variables are held constant, the children living in houses where there were fewer mosquitoes had their probability of being tested positive to malaria reduced by 0.1151 .

The parameters of mothers having secondary education and tertiary education are with a negative sign and statistically at $p<0.01$ and $p<0.05$, respectively. These results show that compared with the children born to mothers that lacked formal education and holding all other variables constant, those children whose mothers had secondary and tertiary education had their probability of being tested positive to malaria reduced by 0.0497 and 0.0988 , respectively. The parameter of a child's age is statistically significant $(\mathrm{p}<0.01)$. This implies that holding other variables constant, if the age of children increased by 1 month, the probability of being tested to malaria increased by 0.0055 . Also, those children with reported anemia were those with higher probability of being tested positive to malaria. The parameters of severe anemia and moderate anemia are with a positive sign and statistically significant $(p<0.01)$. When compared with those without anemia and holding all other parameters constant, the children with severe anemia had their probability of being tested positive to malaria increased by 0.4876 . The results also show that compared with the children with no symptoms of anemia and holding all other variables constant, the children with a reported moderate anemia had their probability of being tested positive to malaria increased by 0.3046 . Similarly, compared with the children with no symptoms of anemia and holding all other variables constant, the children with a reported mild anemia had their probability of being tested positive to malaria increased by 0.1210 .

\section{DISCUSSION}

In analyzing correlates of malaria infection, often little emphasis is placed on the characteristics of the dwellings, which are invariably related to socio-economic characteristics of the households [37]. In addition, because of their direct interaction with children, the role of the mothers in forestalling child morbidity is notably recognized in literature with emphasis on, among others, education, income and access to information [38].

\section{Maternal socio-economic status and the incidence of malaria in the children under 5 years of age}

The results showed higher fertility among the rural women. Similar finding has been reported in literature [39]. This finding can be directly associated with the prevalence of polygamy among rural households in order to meet the family's increasing need of labour on- and off-farm. The results also pointed at majority of the household heads being in their most productive age. This can be explained 
by the obvious cultural and religious differences that can influence marriage and family affairs in Cameroon. It was also found that the rural residents were on average slightly older. Similar finding has been reported and this may have resulted from the tendency of rural urban migration among able bodied youths either for seeking job opportunities or furthering their educational pursuits. However, once migrated, the majority never returned to villages because they mandatorily sought means of livelihoods in urban areas [40].

There was dominance of household headship by males across the economic sectors although a similar finding had been reported earlier [40]. This presupposed the role of culture and religious issues in fashioning gender role in families. Households' headship role by a woman often takes place when the husband is dead or has migrated to the cities in search of better economic fortunes. The fact that more of the children's mothers were alive can be explained by men's involvement in numerous ventures as the bread winners of the house. Such economic hustling exposes them to several health hazards, sometimes resulting in an untimely death. This may as well explain why the percentage of fathers that were alive was lower than that of mothers across all the regions and rural/urban areas.

Those children whose mothers had secondary and tertiary education had their probability of being tested positive to malaria reduced. Maternal education ensures being able to understand and appreciate the use of several methods to control malaria. It may as well be linked to households' wealth, which in turn may ensure good housing condition $[9,27]$. However, as children grow older, the tendency of sleeping under mosquito nets reduces at all times. This can often result in exposure to mosquito bites and malaria [27]. Anemia of whatever degree was also associated with malaria. Similar findings had been reported earlier [7]. Access to media information through possessing a radio reduced probability of malaria infection. Proper communication facilitates is a positive behavior change, which automatically reduces infection rate of a disease. This is critical for malaria transmission, given that radio programmes have assisted policy makers to identify critical channels for net utilization and compliance with safe practices in order to avoid being bitten by mosquitoes. In Cameroon, the impact of "KO Palu" which means "Knock Out Malaria" campaign was investigated and found to positively influence compliance with mosquito net usage and reduction of malaria episodes $[9,41,42]$.

\section{Dwelling characteristics and the incidence of malaria}

The results of the study showed deficiency in dwelling characteristics with some houses built in landslide- and flood-prone areas. Incidences of landslides and flooding are directly associated with recent changes in climate across some African countries [39], especially in some cases where houses are built very close to a riverside. Malaria and several water borne diseases are common health hazards associated with landslide and flood disasters [43,44]. In case of flooding and landslides, displaced households have to seek refuge in places where mosquito bites cannot be perfectly curtailed $[45,46]$. This subjects them to higher vulnerability.

The results also indicated that a higher proportion of urban children (10.68\%) was living in houses built in areas that were prone to flood. This is an indication of peculiar housing problems that are associated with population growth in some urban cities. The problem of sanitation in some urban centers similarly portends chaotic situations in respect of transmission of malaria parasites [47,48].

Additionally, the study found that some children were residing in houses without windows, with broken windows, without screening nets and with incomplete roofs. The rural children suffered from higher deprivation than their urban counterparts. Such a deprivation is also a reflection of economic destitution that often many rural households face. The implication of living in houses with such a feature is that mosquitoes will be able to freely enter the 
house and the likelihood of biting residents is very high. Depending on the location of houses and whether household members stay outside at night, ability to provide basic facilities to prevent entrance of mosquitoes into the dwelling is a major step towards addressing the problem of malaria [49,50].

Similarly, in line with expected protection from mosquito bites due to availability of adequate housing, the presence of holes in the roof affected the children residing in them in such a way that they were exposed to more mosquito bites. In some cases, the fact that houses are not adequately ceiled from the outside makes it possible for mosquitoes to enter the house. However, the presence of window and door nets was reported by some households. Due to their better affluence, the urban households had more coverage of screening nets than their rural counterparts. However, effectiveness of such nets can be hampered if they are damaged or not properly fitted $[46,47]$.

Another dimension of housing characteristics, which was considered in this paper, was access to improved water and sanitation. A water source was considered improved if it was from a borehole, protected spring, protected well and rainfall [49]. Unimproved sources of water can serve as media for contacting other diseases that can weaken the immune system, making it susceptible to malaria. When a source of water is not protected, it can also serve as breeding ground for mosquitoes. It has been found that when households have access to improved water, the incidence of malaria reduces [50]. The results also showed that access to electricity was lower in the rural areas than in the urban ones. Ideally, access to electricity can facilitate use of mosquito nets when the temperature under the net is high because electric fans or air conditioners can be switched on [51].

Probability of malaria infection in the urban areas was lower than in the rural ones. This may have resulted from better access to mosquito nets, which can translate into proper usage due to a high level of formal education. Similarly, the urban residents are more likely going to live in houses with window and door nets. Also, due to their proximity to health centers, the urban households may have access to vital health information that can translate into a reduced malaria infection rate, given that majority of the mothers have some form of formal education. Most importantly, although poorly maintained, drainage systems can constitute breeding grounds for mosquitoes in urban areas, rural areas are often characterized by the presence of nearby bushes for mosquito larva development [9].

Compared with residence in Yaoundé, residence in Adamawa, East, South and South West Regions increased the probability of being infected with malaria. Yaoundé is highly urbanized and the households have better housing facilities and access to mosquito nets. Also, due to hilly nature of the city, it is expected that drainage system is good, so that multiplication of mosquitoes is prevented. Similar finding has been reported based on clinical records from Cameroon [52]. However, it should be emphasized that being located in dry savannah where malaria transmission is expected to be less severe, households in the northern parts of Cameroon are expected to have less exposure to mosquito bites and malaria infections [34].

Compared to those without access, the children in households with access to an improved toilet had lower probability of having malaria infection. The relationship between access to improved water and malaria can be very complex. This can be viewed from the fact that when an unprotected source of water such as a pond, river, stream, well, etc. is close to residential houses, they can serve as breeding ground for mosquito larval, thereby increasing malaria infections. Similarly, denial of access to improved sanitation makes households defecate in nearby bushes. This implies that nearby bushes are not clean and they can facilitate breeding of mosquitoes [53-56].

Residence in landslide prone areas increased the probability of malaria infections among the children. This can be explained by the fact that recent incidences of landslides 
in Cameroon have been motivated by a climate change in a form of excessive rainfall in some specific locations. The impact of too much rainfall on malaria can be overwhelming due to a significant increase in the number of mosquitoes [39]. However, residence in flood-prone areas reduced malaria infection, which is contrary to the expectations. It can as well imply that the households were using adequate protective means against mosquito bites, or that there were no recent incidences of flood. Also, residence in steep hills reduced malaria infection. This is expected and can be due to the presence of free flowing drainage system, which is expected to reduce multiplication of mosquitoes.

\section{Mosquito nets ownership, usage}

and the incidence of malaria in children

\section{under 5 years of age}

Access to mosquito nets was moderately high among the respondents with $64.03 \%$. However, only $23.15 \%$ of the children were sleeping under the nets. Although promotion of the use of ITN for reducing malaria morbidity and mortality among the children under 5 years of age and pregnant women have received some boosts in many developing countries [57-59], the degree of households' compliance and its effectiveness are issues that are somehow subjectively evaluated.

Strategies for controlling malaria in Cameroon now focus on efficient diagnosis, treatment of clinical cases and promotion of insecticide treated nets (ITNs) use [9]. Every country under the global initiative to Roll Back Malaria has been strongly motivated to increase households' access to ITNs [3]. Since 2003 Cameroon government has taken several initiatives to reduce transmission of malaria parasites. Among these there were: distribution of some ITNs freely for the use of pregnant women and children under the age of 5; subsidization of ITN cost; subsidization of artemisininbased combination therapy; and promotion of some trainings for community local health assistants in order to handle some mild cases of malaria infection [8].
The disparities in access to mosquito nets and usage can be explained by free distribution of mosquito nets by the Cameroonian government in order to address the problem of malaria, which is rated above acquired immunodeficiency syndrome (AIDS) and tuberculosis in respect of associated mortality, morbidity and labour days of incapacitation [60]. When compared with other countries, access to mosquito net was lower than that of Papua New Guinea (80.1\%) [61]. The findings also emphasized the fact that the ownership of mosquito nets did not automatically translate into their usage [27]. Although several reasons were given for non-use of a mosquito net, in Cameroon, it had been reported that in some rural areas, freely distributed mosquito nets have been converted into fishing nets [62]. Cases of malaria were also associated with anemia among children. Previous studies have also found association between malaria infection among children and anemia [7,63,64].

The results indicated that some households were not having mosquito nets due to the lack of financial means for its procurement. This is as a result of poverty, which in Cameroon is more or less a rural phenomenon [65]. Some households did not see the need to procure a mosquito net possibly due to the properly fixed windows and/or doors nets. Several alternatives to malaria control had been reported in some studies [9]. This presupposes evaluative mechanisms for detecting a viable means of addressing malaria problem given financial constraints that some households face.

The results further revealed that the households' access to mosquito nets reduced a child's probability of being infected with malaria parasites. This is expected because mosquito nets have been found to reduce mosquito bites which cause malaria infection [66]. However, a major issue concerning the use of a mosquito net is coverage of all household members. Due to its cost, not all household members may be covered, which implies that some households would be still exposed to mosquito bites and be infected by malaria. Therefore, the result goes in line with a priori expectation [67]. 


\section{CONCLUSIONS}

Although Cameroonian government has recently embarked upon mass distribution of mosquito nets as a major step in reducing the socio-economic burden of malaria, many children are still unable to sleep under mosquito nets. The crucial issue for which interventions are needed is how to bridge the gap between ownership and usage. Since government may not provide mosquito nets for everybody, ensuring that they are available at subsidized prices can also help improve the current situation. Similarly, some of the houses inhabited by people were reported to lack windows, doors and other basic facilities.

In conclusion, in Cameroon, ownership of mosquito nets and dwelling characteristics are critical factors influencing infections with malaria. There is a need to ensure compliance with its use since there are disparities between access and the actual usage. Addressing malaria problem in Cameroon should also consider regional disparity in malaria incidence rates, subsidizing the nets for adequate coverage of household members, engagement of radio programmes to educate people on the need to comply with the use of the nets, provision of informal education to women, especially during antenatal period, on how to prevent their children from malaria, and more development of egalitarian society where poverty is fought in order to ensure access to basic housing and social facilities.

\section{ACKNOWLEDGMENTS}

I want to thank Measure DHS for granting the permission to download and use the dataset.

\section{REFERENCES}

1. Russell PF. Man's mastery of malaria. London: Oxford University Press; 1965.

2. Foster WD. A history of parasitology. Edinburgh: Livingstone; 1965.
3. World Health Organization. The African summit on Roll Back Malaria. WHO/CDS/RBM/2000-1722000. Geneva: WHO; 2000.

4. Teklehaimanot A, Mejia P. Malaria and poverty. Ann N Y Acad Sci. 2008;1136:32-7, http://dx.doi.org/10.11 96/annals.1425.037.

5. World malaria report 2012. Factsheet on the world malaria report 2013 [cited 2014 Sep 4]. Available from: http://www. who.int/malaria/media/world_malaria_report_2013/en.

6. World Health Organization. World malaria report 2012. Geneva: WHO Press; 2012.

7. Pemunta NV. The social epidemiology and burden of malaria in Bali Nyonga, Northwest Cameroon. Health Cult Soc. 2013;4(1):20-36.

8. [Ministry of Health: Report on the evolution of malaria cases and access to health centers in the city of Yaounde. Report of the National Programme against malaria in Cameroon]. Cameroon: Ministry of Health; 2010. French.

9. Ndo C, Menze-Djantio B, Antonio-Nkondjio C. Awareness, attitudes and prevention of malaria in the cities of Douala and Yaoundé (Cameroon). Parasit Vectors. 2011;4:181, http://dx.doi.org/10.1186/1756-3305-4-181.

10. Bigoga JD, Manga L, Titanji PK, Coetzee M, Leke GF. Malaria vector and transmission dynamics in coastal South-Western Cameroon. Malar J. 2007;6:5, http://dx.doi. org/10.1186/1475-2875-6-5.

11. Heggenhougen HK, Hackenthal V, Vivek P. Bednet usage and its acceptance at the local level. In: The behavior and social aspects of malaria control: An introduction and annotated biography. Special Programme for Research \& Training in Tropical Diseases (TDR). Social, Economic and Behavioural Research, TDR/STR/SEB/VOL/03.1. Geneva: World Health Organization; 2003. p. 97-106.

12. Miller JM, Korenromp EL, Nahlen BL, Steketee R. Estimating the number of insecticide treated nets required by African households to reach continent-wide malaria coverage targets. JAMA. 2007;297(20):2241-50, http://dx.doi. org/10.1001/jama.297.20.2241. 
13. Kimani EW, Vulule JM, Kuria IW, Mugisha F. Use of insecticide-treated clothes for personal protection against malaria: A community trial. Malar J. 2006;5:63.

14. Mbonye AK, Neema S, Magnussen P. Preventing malaria in pregnancy: A study of perceptions and policy implications in Mukono district, Uganda. Health Policy Plan. 2006;21(1): 17-26, http://dx.doi.org/10.1093/heapol/czj002.

15. Thomson M, Connor S, Bennett S, D'Alessandro U, Milligan P, Aikins M, et al. Geographical perspectives on bed net use and malaria transmission in the Gambia, West Africa. Soc Sci Med. 1996;43(1):101-12, http://dx.doi.org/ 10.1016/0277-9536(95)00346-0.

16. Binka FN, Adongo P. Acceptability and use of insecticide impregnated bed nets in Northern Ghana. Trop Med Int Health. 1997;2(5):499-507, http://dx.doi.org/ 10.1111/j.1365-3156.1997.tb00173.x.

17. Winch PJ, Makemba AM, Makame VR, Mfaume MS, Lynch MC, Premji Z, et al. Social and cultural factors affecting rates of regular re-treatment of mosquito nets with insecticide in Bagamoyo district, Tanzania. Trop Med Int Health. 1997;2(8):760-70, http://dx.doi. org/10.1046/j.1365-3156.1997.d01-376.x.

18. D’Alessandro U, Olaleye B, McGuire W, Langerock P, Bennett S, Aikins M, et al. Mortality and morbidity from malaria in Gambian children after introduction of an impregnated bednet programme. Lancet. 1995;345 (8948):479-83.

19. Hawley WA, ter Kuile FO, Steketee RS, Nahlen BL, Terlouw DJ, Gimnig JE, et al. Implications of the western Kenya permethrin-treated bed net study for policy, program implementation, and future research. Am J Trop Med Hyg. 2003;68(4 Suppl):168-73.

20. Lengeler C. Insecticide-treated bed nets and curtains for preventing malaria. Cochrane Database of Systematic Reviews 2004, Issue 2. Art. No. CD000363, http://dx.doi.org/ 10.1002/14651858.CD000363.pub2.

21. Musa OI, Salaudeen GA, Jimoh RO. Awareness and use of insecticide treated nets among women attending ante-natal clinic in a northern state of Nigeria. J Pak Med Assoc. 2009;59(6):354-8.

22. Eisele TP, Larsen DA, Walker N, Cibulskis RE, Yukich JO, Zikusooka CM, et al. Estimates of child deaths prevented from malaria prevention scale-up in Africa 2001-2010. Malar J. 2012;11:93, http://dx.doi.org/10.1186/1475-2875-11-93.

23. Nevill CG, Some ES, Mung'ala VO, Mutemi W, New L, Marsh K, et al. Insecticide treated bednets reduce mortality and severe morbidity from malaria among children on the Kenyan coast. Trop Med Int Health. 1996;1(2):139-46, http://dx.doi.org/10.1111/j.1365-3156.1996.tb00019.x.

24. Akande TM, Musa IO. Epidemiology of malaria in Africa. Afr J Clin Exper Microbiol. 2005;6(2):107-11.

25. Koudou BG, Ghattas H, Essé C, Nsanzabana C, Rohner F, Utzinger J, et al. The use of insecticide-treated nets for reducing malaria morbidity among children aged 6-59 months, in an area of high malaria transmission in central Côte D'Ivoire. Parasit Vectors. 2010;3:91, http://dx.doi.org/10. 1186/1756-3305-3-91.

26. Keiser J, Utzinger J, Caldas De Castro M, Smith T, Tanner $\mathrm{M}$, Singer B. Urbanization in sub-saharan Africa and implication for malaria control. Am J Trop Med Hyg. 2004;71(2 Suppl):118-27.

27. Kimbi HK, Nana Y, Sumbele IN, Anchang-Kimbi JK, Lum E, Tonga C, et al. Environmental factors and preventive methods against malaria parasite prevalence in rural Bomaka and urban Molyko, Southwest Cameroon. J Bacteriol Parasitol. 2013;4:162, http://dx.doi.org/10.4172/21559597.1000162.

28. Chitra GA, Kaur P, Bhatnagar T, Manickam P, Murhekar MV. High prevalence of household pesticides and their unsafe use in rural South India. Int J Occup Med Environ Health. 2013;26(2):275-82, http://dx.doi.org/10.2478/s13382013-0102-6.

29. Kuate DB. Effects of socioeconomic advantage and women's status on women's health in Cameroon. Soc Sci Med. 1997;44(7):1023-42, http://dx.doi.org/10.1016/S0277-953 6(96)00228-6. 
30. Adelekan DA, Adeodu OO, Thurnham DI. Comparative effect of malaria and malnutrition on plasma concentration of antioxidants micronutrients in children. Ann Trop Paediatr. 1997;17(3):223-7.

31. Nkuo-Akenji TK, Sumbele I, Mankah EN, Njunda AL, Samje M, Kamga L. The burden of malaria and malnutrition among children less than 14 years of age in a rural village of Cameroon. AJFAND. 2008;8(3):252-64.

32. Ekvall H, Arese P, Turrini F, Ayi K, Mannu F, Premji Z, et al. Acute haemolysis in childhood falciparum malaria. Trans R Soc Trop Med Hyg. 2001;95(6):611-7, http://dx.doi. org/10.1016/S0035-9203(01)90095-1.

33. Macintyre K, Keating J, Sosler S, Kibe L, Mbogo CM, Githeko AK, et al. Examining the determinants of mosquito-avoidance practices in two Kenyan cities. Malar J. 2002;1: 1-14, http://dx.doi.org/10.1186/1475-2875-1-14.

34. Nwana TB. Knowledge and utilization of insecticide treated nets to prevent malaria in Cameroon (A case of the Mount Fako Region) [dissertation]. Beppu: Ritsumeikan Asia Pacific University; 2011.

35. National Institute of Statistics (INS). [Démographiqueet Health Survey and Multiple Indicator (EDS-MICS 2011)). Preliminary Report, 2011]. Cameroon: INS and MEASURE DHS; 2012. French.

36. O'Halloran S. Lecture 9: Logit/Probit model [cited 2014 Sep 4]. Available from: http://www.columbia.edu/ so33/ SusDev/Lecture_9.pdf.

37. Yusuf BO, Adeoye BW, Oladepo OO, Peters DH, Bishai D. Poverty and fever vulnerability in Nigeria: A multilevel analysis. Malar J. 2010;9:235, http://dx.doi.org/10.1186/1475-2875-9-235.

38. Bicego GT, Ties Boerma J. Maternal education, use of health services and child survival: An analysis of data from Bolivia DHS survey. Columbia: Institute for Resource Development/Macro Systems, Inc.; 1990 [cited 2014 Jun 15]. Available from: http://dhsprogram.com/publications/publication-wp1-working-papers.cfm.

39. Braatz S. Building resilience for adaptation to climate change through sustainable forest management. In: Meybeck A,
Lankoski J, Redfern S, Azzuand N, Gitz V, editors. Building resilience for adaptation to climate change in the agriculture sector. Proceedings of a Joint FAO/OECD Workshop; 2012 Apr 23-24. p. 117-28.

40. Lynch SG. Income distribution, poverty, and consumer preferences in Cameroon. Cornell Food and Nutrition Policy Program: 1991 [cited 2014 Jun 15]. Available from: http:// www.cfnpp.cornell.edu/images/wp16.pdf.

41. Macintyre K, Littrell M, Keating J, Hamainza B, Miller J, Eisele TP. Determinants of hanging and use of ITNs in the context of near universal coverage in Zambia. Health Policy Plan. 2012;27(4):316-25, http://dx.doi.org/10.1093/heapol/ czr042.

42. Baume CA, Franca-Koh AC. Predictors of mosquito net use in Ghana. Malar J. 2011;10:265, http://dx.doi. org/10.1186/1475-2875-10-265.

43. Landslides leave 10 families in the cold. Kenya Cent. [Internet] [published 2013 May 8; cited 2014 Jun 15]. Available from: http://www.kenyacentral.com/news/79720-landslidesleave-10-families-in-the-cold.html.

44. ACT Alliance [Internet]. Landslide and flash flood in Udomxay province [published 2013 Sept 18; cited 2014 Jun 15]. Available from: http://www.actalliance.org/resources/alerts_ and_situation_reports/Alert37_2013_Laos_Floods.pdf.

45. Affe M. The Punch. Displaced Bakassi children seek FG's help. Punch. [Internet] [published 2013 Dec 24; cited 2014 Jun 15]. Available from: http://www.punchng.com/news/ displaced-bakassi-children-seek-fgs-help.

46. Kilian A, Byamukama W, Pigeon O, Atieli F, Duchon S, Phan C. Long-term field performance of a polyesterbased long-lasting insecticidal net in rural Uganda. Malar J. 2008;7:49, http://dx.doi.org/10.1186/1475-2875-7-49.

47. Skovmand O. Insecticidal bednets for the fight against malaria - Present time and near future. Open Biol J. 2010;3:92-6.

48. Kilian A. How long does a long-lasting insecticidal net last in the field? Public Health J. 2010;21:43-7.

49. World Health Organization; United Nations International Children's Emergency Fund Joint Monitoring 
Programme (JMP) for Water Supply and Sanitation. Types of drinking-water sources and sanitation [cited 2014 Jun 15]. Available from: http://www.wssinfo.org/definitions-methods/ watsan-categories.

50. World Health Organization. Water, Sanitation and Hygiene Links to Health Facts and Figures - 2004 [cited 2014 Jun 15]. Available from: http://www.who.int/water_sanitation_health/en/factsfigures04.pdf.

51. Jobin W. Electric fans - Annual consumption of $1500 \mathrm{Kwhr} /$ cap and no malaria in Africa [cited 2014 Jun 15]. Available from: http://www.malariaworld.org/blog/electric-fans-annual-consumption-1500-kwhrcap-and-no-malaria-africa.

52. Ngom R. Spatial and statistical prediction of urban malaria in Yaoundé: A social and environmental modelling approach for health promotion, 2010 [cited 2015 Mar 10]. Available from: http://opus.ph-heidelberg.de/files/30/Roland_Ngom_Doctoral_thesis_Online.pdf.

53. World Health Organization; United Nations International Children's Emergency Fund Joint Monitoring Programme for Water Supply and Sanitation. Water for life: Making it happen. New York: UNICEF / Geneva: WHO; 2005.

54. Lewis L. Cholera, dengue fever and malaria: The unquestionable linkage to water [cited 2014 Jun 15]. Available from: http://thewaterproject.org/cholera-dengue-fever-malaria-water.

55. World Health Organization. Fact and figures: Water, sanitation and hygiene links to health [cited 2014 Jun 15]. Available from: http://www.who.int/water_sanitation_health/publications/factsfigures04/en.

56. United Nations International Children's Emergency Fund; World Health Organization. Diarrhoea: Why children are still dying and what can be done. New York: UNICEF / Geneva: WHO; 2009.

57. Federal Ministry of Health. The Abuja declaration on Roll Back Malaria in Africa. Extract from African summit on Roll Back Malaria. World Health Organization (WHO) fact sheet 2000. p. 2-12.
58. World Health Organization. Nigeria malaria status. World malaria report 2008. WHO; 2008. p. 99-101.

59. Okafor IP, Odeyemi KA. Use of insecticide-treated mosquito nets for children under five years in an urban area of Lagos State, Nigeria. Niger J Clin Pract. 2012;15(2):220-3, http://dx.doi.org/10.4103/1119-3077.97325.

60. Bongben L. Utilization of mosquito nets below average in Cameroon [Internet]. 2013 [cited 2014 Jun 15]. Available from: https://bongben.wordpress.com/2013/10/02/uttiliza tion-of-mosquito-nets-below-average-in-cameroon.

61. Hetzel MW, Gideon G, Lote N, Makita L, Siba PM, Mueller I. Ownership and usage of mosquito nets after four years of large-scale free distribution in Papua New Guinea. Malar J 2012;11 Suppl 1:192, http://dx.doi.org/10.1186/14752875-11-192.

62. African Spotlight 2013. Cameroon: Malaria on the rise as some use mosquito nets for fishing [cited 2014 Jun 15]. Available from: http://africanspotlight.com/2013/10/08/cameroon-malaria-on-the-rise-as-some-use-mosquito-nets-forfishing.

63. Nielsen NO, Simonsen PE, Magnussen P, Magesa S, Friis H. Cross-sectional relationship between HIV lymphatic filariasis and other parasitic infections in adults in coastal northeastern Tanzania. Trans R Soc Trop Med Hyg. 2006;100(6): 543-50, http://dx.doi.org/10.1016/j.trstmh.2005.08.016.

64. Kagu MB, Kawuwa MB, Gadzama GB. Anaemia in pregnancy: A cross-sectional study of pregnant women in a Sahelian tertiary hospital in Northeastern Nigeria. J Obstet Gynaecol. 2007;27(7):676-9, http://dx.doi. org/10.1080/01443610701612144.

65. International Fund for Agricultural Development. Enabling the rural poor to overcome poverty in Cameroon. 2012 [cited 2014 Jun 15], http://www.ifad.org/operations/projects/ regions/PA/factsheets/ca.pdf.

66. Hetzel MW, Pulford J, Reimer L, Koimbu G, Makita L, Seddon R, et al. Reduction in malaria following the free distribution of mosquito nets in Papua New Guinea [poster]. 2012 [cited 2014 Jun 15]. Available from: http:// 
operations.9810rotary.org.au/files/2012/04/Poster-RAM032012-portrait.pdf.

67. Choi HW, Breman JG, Teutsch SM, Liu S, Hightower AW, Sexton JD. The effectiveness of insecticide-impregnated bed nets in reducing cases of malaria infection: A metaanalysis of published results. Am J Trop Med Hyg. 1995; 52(5):377-82.

This work is available in Open Access model and licensed under a Creative Commons Attribution-NonCommercial 3.0 Poland License - http://creativecommons.org/ licenses/by-nc/3.0/pl/deed.en. 